\title{
Long-term effect of autologous progenitor cell therapy to induce neo angiogenesis in patients with critical limb ischemia transplantated via intramuscular vs combined intramuscular and distal retrograde intra venous
}

\author{
Luis Padilla ${ }^{1,2^{*}}$, Juan Rodriguez-Trejo ${ }^{3}$, Ignacio Escotto ${ }^{3}$, Manuel López-Hernandez ${ }^{4}$, \\ Mauricio González ${ }^{5}$, José De Diego ${ }^{6}$, Neftaly Rodrgiuez ${ }^{3}$, Jesús Tapia², Takeshi Landero', \\ Carranza Pilar Hazel ${ }^{1}$, Horacio Juarez Olguin ${ }^{1}$, Mauricio Di Silvio ${ }^{1,7}$, Paul Mondragon-Teran ${ }^{8}$ \\ ${ }^{1}$ Department of Experimental Surgery, Microsurgery Unit, Centro Medico Nacional "20 de Noviembre" ISSSTE, Mexico City, \\ Mexico; ${ }^{*}$ Corresponding Author: 1padilla@issste.gob.mx \\ ${ }^{2}$ Surgery Department, Faculty of Medicine, Universidad Nacional Autonoma de Mexico, Mexico City, Mexico \\ ${ }^{3}$ Angiology, Vascular and Endovascular Surgery Unit, Centro Medico Nacional "20 de Noviembre" ISSSTE, Mexico City, Mexico \\ ${ }^{4}$ Haematology Unit, Centro Medico Nacional "20 de Noviembre" ISSSTE, Mexico City, Mexico \\ ${ }^{5}$ Bank of Blood Unit, Centro Medico Nacional "20 de Noviembre" ISSSTE, Mexico City, Mexico \\ ${ }^{6}$ Pediatric Hematology Unit Centro Medico Nacional '20 de Noviembre' ISSSTE, Mexico City, Mexico \\ ${ }^{7}$ Department of Research, Hospital General de México OD, Secretaria de Salud México, Mexico City, Mexico \\ ${ }^{8}$ Department of Biomedical Research, Centro Medico Nacional “20 de Noviembre” ISSSTE, Mexico City, Mexico
}

Received 13 August 2012; revised 15 September 2012; accepted 11 October 2012

\section{ABSTRACT}

Critical limb ischemia is a medical condition that decreases blood flow and limb oxygen supply; this disease in its late stages of progression leads to only two possible options: either surgical bypass revascularization or limb amputation. We investigated a novel method using autologous transplantation of progenitor cells derived from mobilized peripheral blood bone marrow mononuclear cells to evaluate its longterm effect as a cell therapy to induce neo-angiogenesis and restore blood flow in the affected ischemic limbs. A total of 20 ischemic limbs from critical limb ischemia diagnosed patients, non candidates to surgical revascularization were transplanted with autologous progenitor cells by either intramuscular combined with intravenous (group $A$ ) or intramuscular (group B) procedure. Patients were monitored during 31 months. Treatment efficacy was evaluated according to the following parameters: ankle brachial index which increased at a range of 0.29 - 1.0 in group $A$ and $0.40-0.90$ in group $B$; pain-free walking distance which increased at a range of $50-600 \mathrm{~m}$ in group $A$ and $50-300 \mathrm{~m}$ in group $B$; and blood perfusion (measured by La- ser Doppler) which increased at a range of 48 299 in group A and $135-225$ in group B. We achieved $90 \%$ treated ischemic limbs free of amputation in both transplanted groups. Results here described provide a safe, efficient and minimally invasive therapy with progenitor cells to induce angiogenesis and preserve limbs from amputation in CLI diagnosed patients.

Keywords: Neo-Angiogenesis; Cell therapy; Critical Limb Ischemia; Progenitor Cells; Blood Perfusion

\section{INTRODUCTION}

Peripheral arterial disease (PAD) is a medical problem that comprises the obstruction of blood flow in the arteries causing inadequate oxygen supply to diverse tissues. This disease currently affects approximately 12 million people in the United States of America (USA) [1]. The death risk for people with PAD is 10 to 15 times greater than the death risk for subjects free from this disease as shown in a 10 years follow up study [2]. PAD in lower extremities is mainly expressed with intermittent claudication (IC) which is an early manifestation of pain during ambulation; as disease progresses pain is presented even at rest and patients usually develop a blood flow decrease which leads to ischemic ulcerations and in late stages 
gangrene requiring minor or major amputations, thus completing the natural story for critical limb ischemia (CLI) [3-5]. Diabetic patients are at a higher risk of developing such CLI condition, since $30 \%$ of them will present it earlier in life, compared with non-diabetic population [6,7]; besides, PAD in diabetes mellitus disease is more diffuse and severe, mainly affecting the lower extremities vasculature, while the non-diabetic patients with PAD have a higher aorto-iliac incidence $[8,9]$. CLI is a growing medical problem and has an estimated incidence of $11 \%$ in the general population and $15 \%$ in adults over 55 years old; it also has been reported with an incidence of 500 to 1000 individuals per million each year [10]. The reported mortality rates due to CLI has been $20 \%, 35 \% 70 \%$ and up to $100 \%$ for $1,2,5$ and 10 years respectively and at least $50 \%$ of patients will undergo major limb amputation within 6 to 12 months [11-13]. Current treatments for CLI patients include serum lipid levels reduction, antiplatelet (i.e. cilostasol) and antihypertensive drugs showing limited efficacy in CLI severe stages [14,15]. Although surgical revascularization remains as the most appropriate CLI therapy aimed to prevent limb loss, it is not suitable for at least $30 \%$ of patients because of extent of the disease and the lack of proper non damaged autologous vasculature; which leaves amputation as the only option if CLI has progressed beyond the point of salvage, vascular surgery is too risky or life expectancy is very low $[16,17]$. Incluiding only USA 100,000 major limb amputations are performed every year due to PAD with an annual cost of more than 13 billion US dollars [18]. Patients with CLI who are not eligible for revascularization have no effective treatment option. Despite there is no Federal Drug Administration (FDA) approved therapy for these CLI patients, there has been several research groups reporting different strategies towards the establishment of progenitor cell therapies to allow the formation of new blood vessels (neo-angiogenesis) as a method to salvage ischemic limbs through autologous transplantation of progenitor cells derived from Bone Marrow-Mononuclear Cells (BM-MNC) [18-23]. At least 40 research groups have obtained promising results with BM-MNC transplantation as progenitor cell therapy treatment for CLI patients, supporting evidence to establish this procedure as an alternative to improve blood perfusion through neo-angiogenesis and to avoid amputation [3, 18]. To reach a maximum local cell concentration, Bartsch et al. [21], performed 13 intramuscular and intra-arterial transplantation of BM-MNC obtained from iliac crest bone marrow aspiration and purified through ficoll gradient technique, this procedure resulted in the improvement of the ankle brachial index (ABI); in contrast, the 12 patients in the control group with no cell transplant showed a statistically significant reduction of ABI and venous occlusion plethysmography at rest. Using a rat ischemic limb model we previously demonstrated the induction of effective neo-vascularization after bone marrow mononuclear cell $\left(\mathrm{CD}^{34+}\right.$ and $\left.\mathrm{CD}^{133+}\right)$ transplantation into surgically induced fibrocollagenous tunnels used as scaffolds to enhance cell survival and differentiation [24]. In a second experimental study, our group used dogs as an ischemic limb model confirming that transplantation of mobilized BM-MNC to peripheral blood through the use of Granulocyte Colony-Stimulating Factor (G-CSF) statistically significant increased angiogenesis as compared with cell transplant without G-CSF treatment [25]. Based on the evidence of neo-angiogenesis as a result of mobilized BM-MNC autologous transplantation on these experimental models, we obtained the ethical and research institution committee approval to start a clinical trial in humans for the progenitor cell therapy of CLI patients. In this report we analyze the efficacy of Mobilized BM-MNC transplantation comparing combined procedure intramuscular and distal retrograde-intravenous (saphenous vein) transplantation (IM + IV) versus intramuscular (IM) standard transplantation procedure.

\section{MATERIALS AND METHODS}

\subsection{Trial Profile}

The institutional board approved this prospective, controlled, randomized study; all enrolled patients provided written informed consent; all surgical procedures were conducted by senior expert surgeon (PL and RTJ).

\subsection{Patient's Inclusion Criteria}

Patients older than 18 years old presenting severe lower limb obstructive arterial disease classified as Fontaine stage IIb (Incapacitant intermittent claudication), Fontaine stage III (pain at rest), Rutherford 4, with an ankle-brachial index (ABI) lower than 0.6, and who were non candidates to surgical bypass revascularization nor to endovascular procedure.

\subsection{Patient's Exclusion Criteria}

Patients with any neoplasia history in the last 10 years, patients with 1 year of life expectancy, patients with severe renal failure, severe malnutrition, or systemic chronic infectious disease at any clinical stage (Hepatitis B, C or HIV infection).

The parameters to evaluate were procedure's safety, treatment efficacy, ABI, blood perfusion and pain-free walking distance evolution. Patients of both experimental and control groups were monitored by measuring those 
parameters at $0,3,12$ months after progenitor cell transplant and at 18, 24 and 31 months after cell transplant therapy to evaluate the ratio of patients free of limb amputation.

\subsection{Study Design}

The study was designed as a randomized prospective controlled clinical trial and its main goal was to improve blood perfusion through neo-angiogenesis and to salvage patient's ischemic limbs. 20 critical ischemic affected limbs (Fontaine II-b, Fontaine III and Rutherford 4) were evaluated in 14 patients non candidates to any form of revascularization who accepted to participate in the study and were included in the trial according to the established inclusion criteria. Limb ischemia diagnosis was based on Laser Doppler blood flow measurements $(\leq 31$ perfusion units), ankle brachial index $(\leq 0.6)$ and painfree walking distance $(\leq 200 \mathrm{~m})$. Patients were randomly divided into two main groups according to the following transplant strategy (as shown in Figure 1):

Group A: 10 ischemic limbs from patients transplanted with progenitor cells using a combination of intramuscular and distal retrograde-intravenous (saphenous vein) transplant. Group A is referred in this report as IM + IV (Intramuscular + Intravenous).

Group B (control group): 10 ischemic limbs from patients with progenitor cell intramuscular transplant. Group $\mathrm{B}$ is referred in this report as IM (intramuscular).

\subsection{Cell Harvest}

Mobilization of Bone Marrow-Mononuclear Cells (B$\mathrm{M}-\mathrm{MNC}$ ) to peripheral blood was achieved by a daily subcutaneous administration of $5 \mu \mathrm{g}$ of Granulocyte Colony-Stimulating Factor (G-CSF) (Roche) during 5 consecutive days at early morning. Mobilized Peripheral Blood Mononuclear Cells (M-PBMNC) were harvested on the 5 th day of treatment by apheresis procedure using a continuous flow COBE-Spectra blood cell automated separator (COBE BCT, Lakewood CO., USA) and a double puncture technique using citrate plus glucose as anticoagulant and physiologic solution as primer. Apheresis was performed as a two-step procedure involving extraction and re-infusion using a Mahurkar or Niagara catheter and extraction/infusion flow speeds between 50 $55 \mathrm{~mL} \cdot \mathrm{min}^{-1}$. For all patients a $60 \mathrm{~mL}$ standard amount of progenitor cell suspension per ischemic limb was obtained at the end of the apheresis procedure.

\subsection{Cell Analysis}

$\mathrm{CD}^{34+}$ (hematopoietic) and $\mathrm{CD}^{133+}$ (angioblast) mouse anti human antibody (Beckton Dickinson, Ca, USA) cell marker were used to confirm progenitor cell phenotyperespectively by flowcytometry analysis using a FAC

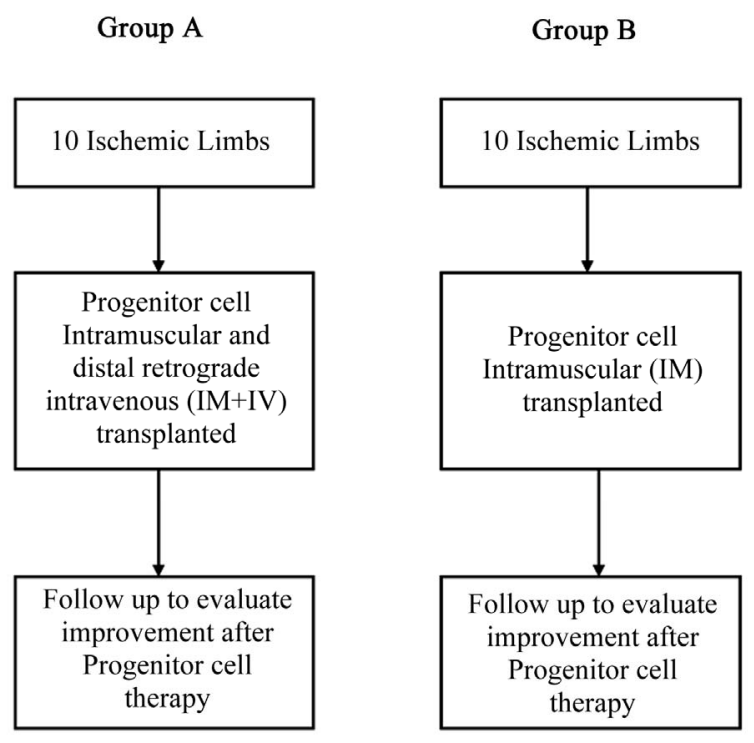

Figure 1. Study design. A total of 14 patients were recruited for this study achieving 10 ischemic limbs per group. Some of the patients presenting both ischemic limbs were included as one of the ischemic limbs in group A and the second ischemic limb in group B.

SCalibur and Cell Quest Pro Software (Becton Dickinson, $\mathrm{Ca}, \mathrm{USA}$ ). Cell count was manually obtained using a haemocytometer.

\subsection{Surgical Technique}

Ultrasound guided punctures on the affected limb muscle compartments were performed under epidural blockade and light sedation using a catheter needle BD Insyte $(16 \mathrm{GA}-1.77 \mathrm{IN})(17 \times 45 \mathrm{~mm})$. The $60 \mathrm{~mL}$ M-PBMN cell suspension per ischemic limb were distributed as follows: $10 \mathrm{~mL}$ in the internal vastus compartment, $10 \mathrm{~mL}$ in the external vastus compartment, 10 $\mathrm{mL}$ in the anterior tibial muscle compartment, $10 \mathrm{~mL}$ in the deep posterior muscle compartment and $10 \mathrm{~mL}$ in the superficial posterior muscle compartment. For group A, as part of the surgical procedure, the major saphenous vein was localized at the internal malleolus level, at this site a small incision was performed in order to dissect the vein and isolate it using chromic catgut 3 - 0 sutures. Afterwards the vein was temporarily ocluded in a proximal direction and a catheter BD Insyte (16GA-1.77IN) $(17 \times$ $45 \mathrm{~mm}$ ) was placed by direct puncture in order to perform a regional distal retrograde heparinization $(1 \mathrm{~mL}$ of heparine diluted 1:1000 $+9 \mathrm{~mL}$ saline solution). A manual tourniquet was applied to avoid the venous flow to return for 10 minutes followed by the distal retrograde intravenous application of the last $10 \mathrm{~mL}$ cell suspension (Figure 2). For group B, $12 \mathrm{~mL}$ instead of $10 \mathrm{~mL}$ of $\mathrm{M}$ PBMN cell suspension were distributed between the 5 muscles compartments as previously mentioned. 


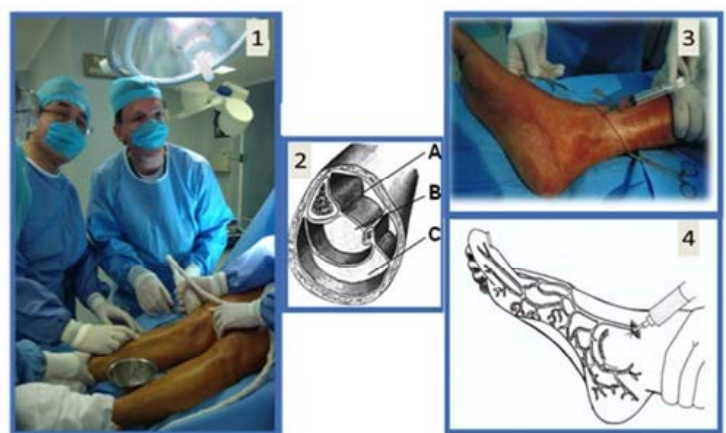

Figure 2. Surgical technique used to induce neo-angiogenesis. Cell transplant was performed ultrasound guided (1), cells were transplanted at different muscle compartments such as: internal and external vastus compartments, anterior tibial muscle compartment (2A), deep posterior muscle compartment (2B), superficial posterior muscle compartment (2C) and at internal malleolus level (3 and 4).

\subsection{Lasser Doppler Technique}

Blood flow by Laser Doppler measurement is a standard technique for real time measurement of tissue perfusion at micro-vascular level. This technique was first reported in 1964 by Yeh and Cummins [26], and the units of Laser Doppler are given in tissue-Perfusion Units (PU); such PU was standardized through the use of a suspension of latex spheres in movement. This method is non invasive, highly sensitive to local perfusion and useful for continuous monitoring if necessary. A signal proportional to red blood cells (RBC) perfusion is displayed in the screen of the Laser Doppler equipment; this signal represents the transport of RBC through microvasculature [27]. Patient's blood flow measurements were performed by Lasser Doppler technique using a Periflux System 5000 (Perimed Instruments, Stockholm Sweden) prior to the transplant procedure and at 3 and 12 months post transplant in both groups. Lasser Doppler measurements were performed for at least 2 minutes for baseline values prior to temperature increase as stimulus to record RBC perfusion units (See Figure 3).

\subsection{Statistical Analysis}

A database corresponding to quantitative baseline and post treatment values for blood perfusion and ABI per patient was used for statistical analysis. Changes from baseline to 3 and 12 months variables were analyzed by paired t-test according to normal distribution. Statistical significance was assumed for $\mathrm{p}<0.05$ value. All statisticcal analysis was performed with SPSS 16.0 statistical software.

\section{RESULTS}

\subsection{Clinical Characteristics}

Fourteen patients with severe CLI (Fontaine IIb, Fon- taine III, Rutherford 4) were recruited, transplanted, evaluated and monitored during 31 months. Clinical characteristics from recruited patients are shown in Table 1(a) and Table 1(b) shows ABI and pain free-walking distance values prior to treatment (defined as time zero- $-t_{0}$ ) and post treatment at 12 months $\left(\mathrm{t}_{12}\right)$.

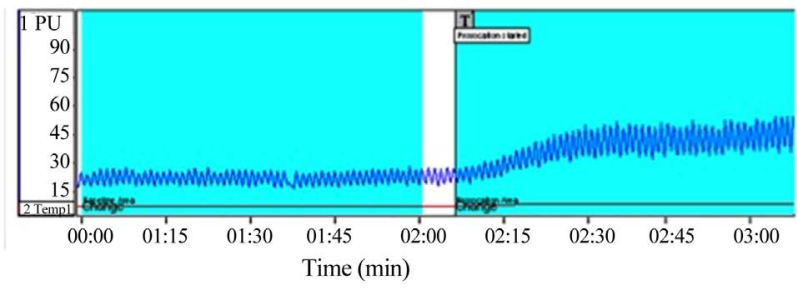

(a)

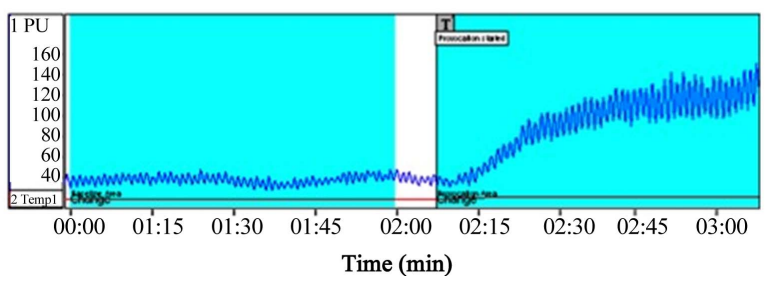

(b)

Figure 3. Representative blood flow measured by Laser Doppler prior to transplant (a) and 12 months post transplant (b).

Table 1. (a) Patient clinical characteristics; (b) Clinical follow up after 12 months post transplantation.

(a)

\begin{tabular}{ccc}
\hline $\begin{array}{c}\text { Clinical } \\
\text { Characteristic }\end{array}$ & $\begin{array}{c}\text { Group A (IM + IV) } \\
\mathbf{N = 1 0}\end{array}$ & $\begin{array}{c}\text { Group B (IM) } \\
\mathbf{N = 1 0}\end{array}$ \\
\hline Smoking & 8 & 5 \\
Hypercholesterolemia & 5 & 6 \\
Diabetes Mellitus & 6 & 2 \\
Arterial Hypertension & 8 & 6 \\
Myocardial Infarct & 2 & 2 \\
\hline
\end{tabular}

(b)

\begin{tabular}{ccc}
\hline Parameter & Group A (IM + IV) & Group B (IM) \\
\hline Limb Amputation & $1^{*}$ & $1^{* *}$ \\
$\begin{array}{c}\text { Pain-Free Walking } \\
\text { Distance (m) Range } \\
(\text { min - max })\end{array}$ & $50-600$ & $50-300$ \\
$\begin{array}{c}\text { ABI Range } \\
(\text { min - max })\end{array}$ & $0.29-1.0$ & $0.40-0.90$
\end{tabular}

Blood Flow (PU) Range (min - max)

$48.82-299.02 \quad 135.13-225.31$

Limb amputation on the 8th month post transplant; ${ }^{* *}$ Limb amputation on the 6th month post transplant. 


\subsection{Transplantated Cell Number}

Progenitor cell phenotype was identified by flowcytometry with $\mathrm{CD}^{34+}$ and $\mathrm{CD}^{133+}$ cell markers (as previously described). The total transplanted cell number per ischemic limb were $17.4 \pm 8 \times 10^{6} \mathrm{CD}^{34+}$ cells for group $\mathrm{A}$, and $15 \pm 5 \times 10^{6} \mathrm{CD}^{34+}$ cells for group $\mathrm{B}$; meanwhile the total transplanted $\mathrm{CD}^{133+}$ cells for group A were 2.86 $\pm 5.96 \times 10^{7}$ and $3.01 \pm 5.91 \times 10^{7}$ for group B.

\subsection{Effect of Transplantated Progenitor Cells}

Patients were monitored at 0, 3, and 12 months post progenitor cell transplant; parameters evaluated included: Pain free walking distance (reported in meters), ABI, blood flow reported as perfusion units, angiography and ischemic limbs free of amputation (monitored during
31 months post transplant). At 31 months post treatment period it was reported 1 limb amputation in each group, A and B (Tables 1(b) and 2), interestingly both patients were diabetics. Average values for pain-free walking distance parameter increased from $60 \pm 39 \mathrm{~m}$ pre-transplant to $207 \pm 198 \mathrm{~m}$ at 12 months post-transplant for group A, and from $87 \pm 69 \mathrm{~m}$ pre-transplant to $172 \pm 127 \mathrm{~m}$ at 12 months post-transplant for group B. ABI parameter showed an increase from $0.42 \pm 0.14$ pre-transplant to $0.70 \pm 0.21$ at 12 months post-transplant for group $\mathrm{A}$, and from $0.44 \pm 0.09$ pre-transplant to $0.62 \pm 0.15$ at 12 months post-transplant for group B. Blood perfusion (measured by Laser Doppler) increased from15.8 \pm 9.3 pre-transplant to $205.8 \pm 116.7$ at 12 months post-transplant for group $\mathrm{A}$, and from $16.6 \pm 7$ acute myocardial infarction. There were no reported adverse effects due to cell transplant procedure. Blood flow perfusion units

Table 2. Baseline and monitored clinical parameters.

\begin{tabular}{|c|c|c|c|c|c|c|c|c|c|c|}
\hline Extremity & Limb & $\begin{array}{c}\text { Age } \\
\text { (years) }\end{array}$ & Gender & ABI $\mathbf{t}_{0}$ & ABI $t_{12}$ & $\begin{array}{c}\text { Pain free } \\
\text { walking } \\
\text { distance } \\
\text { to }_{0} \\
\text { (Meters) }\end{array}$ & $\begin{array}{c}\text { Pain free } \\
\text { walking } \\
\text { distance }_{\mathrm{t} 12} \\
\text { (Meters) }\end{array}$ & $\begin{array}{c}\text { Blood } \\
\text { perfusion } \\
\left(t_{0}\right)\end{array}$ & $\begin{array}{c}\text { Blood } \\
\text { perfusion } \\
\left(\mathbf{t}_{3}\right)\end{array}$ & Observation \\
\hline \multicolumn{11}{|c|}{ Group A (IM + IV) } \\
\hline 2 & $\mathrm{R}$ & 72 & M & 0.40 & 0.50 & 100 & 150 & 6.46 & 13.53 & Salvage \\
\hline 3 & $\mathrm{U}$ & 79 & $\mathrm{~F}$ & 0.20 & 0.80 & No data & No data & 8.99 & 30.53 & Salvage \\
\hline 4 & $\mathrm{U}$ & 59 & M & 0.50 & 0.70 & No data & No data & 8.23 & 6.10 & Amputate \\
\hline 5 & $\mathrm{R}$ & 67 & $\mathrm{~F}$ & 0.86 & 0.93 & 100 & 350 & 14.07 & 17.23 & Salvage \\
\hline 6 & $\mathrm{R}$ & 54 & $\mathrm{~F}$ & 0.50 & 0.50 & 50 & 50 & 30.60 & 38.27 & Salvage \\
\hline 7 & $\mathrm{R}$ & 63 & M & 0.26 & 0.55 & 10 & 100 & 30.56 & 42.10 & Salvage \\
\hline 8 & $\mathrm{U}$ & 70 & $\mathrm{~F}$ & 0.40 & 0.80 & No data & No data & 10.56 & 39.20 & Salvage \\
\hline 9 & $\mathrm{R}$ & 68 & M & 0.36 & 0.70 & 40 & 600 & 20.20 & No data & Salvage \\
\hline 10 & $\mathrm{~L}$ & 64 & $\mathrm{~F}$ & 0.50 & 0.29 & 100 & 100 & 12.70 & 31.00 & Salvage \\
\hline \multicolumn{11}{|c|}{ Group B (IM) } \\
\hline 1 & $\mathrm{R}$ & 67 & M & 0.50 & 0.50 & 150 & 1200 & 7.4 & 17.26 & Salvage \\
\hline 2 & $\mathrm{~L}$ & 67 & M & 0.50 & 0.60 & 150 & 1200 & 14.1 & 31.20 & Salvage \\
\hline 3 & $\mathrm{~L}$ & 72 & M & 0.40 & 0.60 & 100 & 150 & 14.49 & 16.09 & Salvage \\
\hline 4 & $\mathrm{~L}$ & 54 & $\mathrm{~F}$ & 0.60 & 0.50 & 50 & 50 & 8.97 & 52.38 & Salvage \\
\hline 6 & $\mathrm{R}$ & 70 & $\mathrm{~F}$ & 0.40 & 0.80 & 10 & 50 & 18.70 & 37.40 & Amputate \\
\hline 7 & $\mathrm{R}$ & 64 & $\mathrm{~F}$ & 0.50 & 0.40 & 100 & 100 & 15.61 & 24.15 & Salvage \\
\hline 8 & $\mathrm{R}$ & 63 & M & 0.26 & 0.50 & 10 & 100 & 30.56 & 42.10 & Salvage \\
\hline 9 & $\mathrm{R}$ & 77 & $\mathrm{~F}$ & 0.40 & 0.90 & 20 & 100 & No data & No data & Salvage \\
\hline 10 & $\mathrm{R}$ & 78 & M & 0.40 & 0.70 & No data & No data & No data & No data & Salvage \\
\hline
\end{tabular}


measured by Laser Doppler (as described in Materials and Methods), showed a significant improvement by an average of 14 fold increase $(p<0.05)$ in the case of group $A$ and a 10 fold increase $(p<0.05)$ for group B as compared with the corresponding baseline blood flow measurements for each group. These results suggest that despite both transplant procedures resulted in an important blood flow increase, the effect was higher when progenitor cells were transplanted using a combined intramuscular-intravenous method. Figure 4 shows blood perfusion from 8 critical ischemic limbs at pre transplant, at 3 and 12 months post transplant as evidence on the increase of blood perfusion after treatment for both groups Figure 5 shows average perfusion unit values for group A and group B pre and post transplant. Angiographic base line (time zero) index and blood perfusion at 12 months time point, were not performed in all patients due to logistic follow up limitations, however at least 6 patients were subjected to angiography.

Figure 6 shows angiography pre and post transplant for one of the patients included in group A and one in the group B as an example of neo-angiogenesis due to progenitor cell transplant. The neo-angiogenesis process was confirmed with the increase in the blood flow perfusion as shown in Figures 4 and 5. Despite ABI, pain free walking distance and blood perfusion parameters were not measured in most of patients at 24 and 31 months, the beneficial effects of treatments were maintained as no limb amputations were performed.

\section{DISCUSSION}

In this study, we found that CLI diagnosed patients treated by any of both procedures, either A or B progenytor cell transplanted groups, induced neo-angiogenesis improving all clinical parameters and avoiding limb amputation as $90 \%$ of limbs in each group were

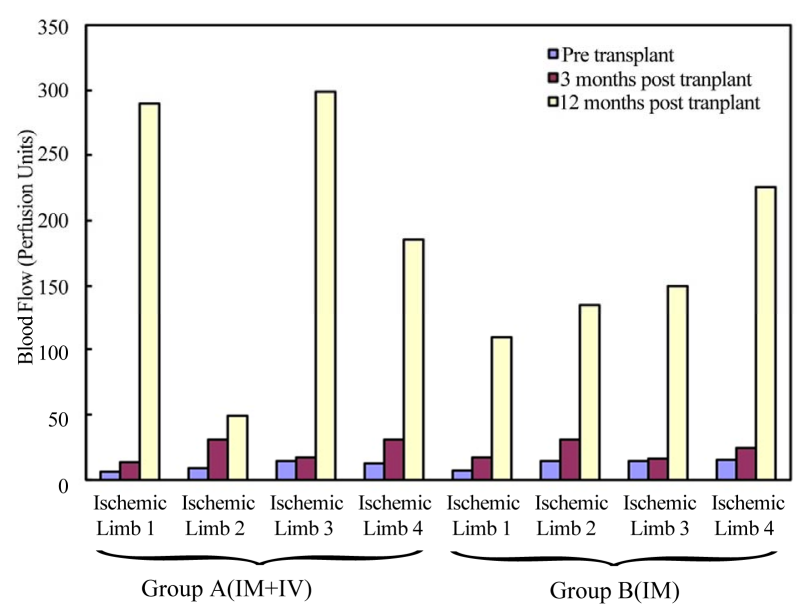

Figure 4. Blood flow given as perfusion units at pre transplant, 3 and 12 months post transplant.

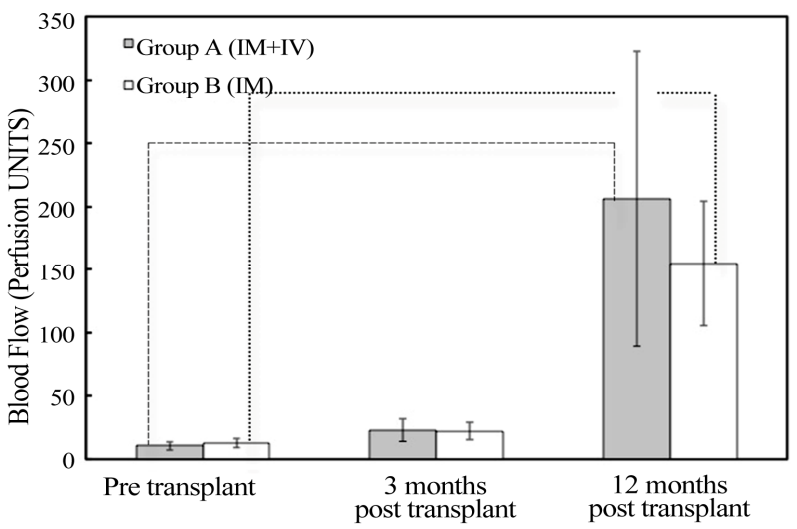

Figure 5. Average PU values for group A and group B. Comparison of blood perfusion between baseline values (pre transplant) and 12 months post transplant resulted in statistically significant differences for (dashed line) group A ( $\mathrm{p}<$ $0.05)$ and (dotted line) group B $(\mathrm{p}<0.05)$.

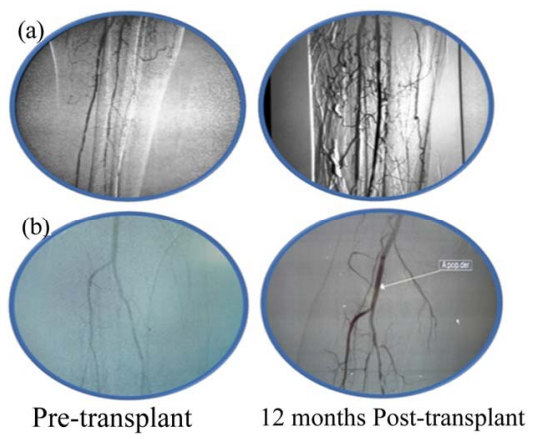

Figure 6. Angiography performed at pre-transplant and 12 months post transplant. Angiography for: (a) one patient from group A and (b) one patient from group B.

saved. It was found a higher efficiency in terms of blood perfusion, ABI and pain-free walking distance when cell transplant was performed with a combined intra muscular and intra venous procedure; however there was no statistical significant difference between groups. We previously performed the transplant of progenitor cells into surgically induced fibrocollagenous tunnels to a total of 8 ischemic limbs; we initially observed a significant clinical improvement in 5 of the ischemic limbs while the other 3 showed non favorable clinical outcome with improvement in vascular proximal blood perfusion but developed necrosis in toes (non published data). We concluded that for those 3 patients the transplant technique did not allow transplanted cells to reach toe's capillaries. Based on these results, we developed a new protocol in CLI induced rats (Sprague Dawley) as a model in order to allow transplanted cells to reach toe's capillaries; we demonstrated that by adding a distal retrograde-intravenous injection of cells, higher levels of angiogenesis 
were produced as compared with intramuscular cell transplant. We also observed that mononuclear cells attached to the smallest capillary segment used as a scaffold increased survival, proliferation, and cell differentiation towards endothelial cell type [28]. Tepper [29] and Law all [30] demonstrated that angiogenesis or vasculogenesis induction requires the ischemic initial stimulus and the muscle inflammatory response that releases cytokines and growth factors (such as VEGF, bFGF, SDF-1, PDG$\mathrm{BB}, \mathrm{IGF}-1$, TGF-B) that activate proliferation, migration and tubulization of endothelial cells. These findings support the use of muscle as the main target for progenytor cell transplant, however we showed that combined intramuscular and intravenous transplant technique provides a higher transplant efficiency as demonstrated in our previous animal model report [26]. A similar 12 months follow up study reported by Van Tongeren et al. [31] demonstrated a higher efficiency when combined intramuscular and intra-arterial transplant strategy was used in comparison with only intramuscular transplant. The main results of our study is the evidence that both transplant procedures increases blood perfusion, ABI and pain free walking distance; showing slightly higher results for combined intramuscular-intravenous group. More importantly, improvements achieved by progenitor cell transplant in this study, were maintained for up to 31 months achieving $90 \%$ of the limbs preserved from amputationn.

\section{CONCLUSION}

Progenitor cell therapy described in this study is a minimally invasive therapeutic option for patients with critical limb ischemia. Both, intramuscular and combined intramuscular-intravenous autologous progenitor cell transplant led to a substantial increase in blood flow perfusion, pain-free walking distance and ankle brachial index. Despite there was no statistical significance between groups, a higher blood perfusion (measured by laser Doppler) was observed when progenitor cells were transplanted combining intramuscular-intravenous as compared with intra muscular procedure. Transplant of progenitor cells described here provides a safe and reliable cell therapy for CLI diagnosed patients who are not candidates for invasive surgical revascularization.

\section{ACKNOWLEDGEMENTS}

We would like to acknowledge to Reneé Acosta and Paola Lares Juárez for their help on the revision of the manuscript.

\section{REFERENCES}

[1] Ouriel, K. (2001) Detection of peripheral arterial disease in primary care. The Journal of the American Medical Association, 286, 1380-1381.

doi:10.1001/jama.286.11.1380

[2] Criqui, M.H., Langer, R.D., Fronek, A., Feigelson, H.S., Klauber, M.R., McCann, T.J. and Bronwer, D. (1992) Mortality over a period of 10 years in patients with peripheral arterial disease. The New England Journal of Medicine, 326, 381-386. doi:10.1056/NEJM199202063260605

[3] Aranguren, X.L., Verfaillie, C.M. and Luttun, A. (2009) Emerging hurdles in stem cell therapy for peripheral vascular disease. Journal of Molecular Medicine, 87, 3-16. doi:10.1007/s00109-008-0394-3

[4] Ouriel, K. (2001) Peripheral arterial disease. The Lancet, 358, 1257-1264. doi:10.1016/S0140-6736(01)06351-6

[5] Luther, M., Lepantalo, M., Alback, A. and Mazke, S. (1996) Amputation rates as a measure of vascular surgical results. British Journal of Surgery, 83, 241-244. doi: $10.1002 /$ bjs. 1800830229

[6] Coffman, J. D. (1991) Intermittent claudication-Be conservative. The New England Journal of Medicine, 325, 577-578.

[7] Beker, G.J., Furguson, J.G., Bakal, C.W., McKinnison, M.G.K., et al. (1993) Angioplasty, bypass surgery and amputation for lower extremity peripheral arterial disase in Maryland: A closer look. Radiology, 186, 635-638.

[8] Rutherford, R.B., Flanigon, D.P., Gupta, S.L., Johnsin, K., et al. (1986) Suggested standards for reports dealing with lower extremity ischemia. Journal of Vascular Surgery, 4, 80-94.

[9] Deweese, J.A., Leather, R. and Porter, J. (1993) Practice guidelines: Lower extremity revascularization. Journal of Vascular Surgery, 18, 280-294. doi:10.1016/0741-5214(93)90609-P

[10] Norgen, L., Hiatt, W.R., Dormandy, J.A., et al. (2007) TASC II working group inter society consensus for the management of pheripheral artherial disease (TASC II). European Journal of Vascular and Endovascular Surgery, 33, 1-75.

[11] Di Stefano, R., Limbruno, U., Barone, D. and Balbarini, A. (2004) Therapeutic angiogenesis of critical lower limb ischemia review of the literature and prospects of research on stem cells. Italian Heart Journal, 5, 1-13.

[12] Boccalon, H., Lehert, P. and Mosnier, M. (2000) Assessment of the prevalence of atherosclerotic lower limb arteriopathy in France as a systolic index in a vascular risk population. Journal Des Maladies Vasculaires, 25, 38-46.

[13] The European Agency for the Evaluation of Medicinal Products, Committee for Proprietary Medicinal Products. (2002) Notes for guidance on clinical investigation of medicinal products for the treatment of peripheral arterial occlusive disease. CPMP/EWP714/98.

[14] Marston, W.A., Davies, S.W., Armstrong, B., Farber, M.A., Mendes, R.C. and Fulton, J.J. (2006) Natural history of limbs with arterial insufficiency and chronic ulceration treated without revascularization. Journal of Vascular Surgery, 44, 108-114. doi:10.1016/j.jvs.2006.03.026

[15] Hilleman, D.E. (1998) Management of peripheral arterial. 
Disease. American Journal of Health Promotion, 55, 521-527.

[16] Dormady, J.A. and Rutherford, R.B. (2000) Management of peripheral arterial disease (PAD). TASC working group. Journal of Vascular Surgery, 31, S1-S278.

[17] Aronow, W.S. (2005) Management of peripheral arterial disease. Cardiology in Review, 13, 61-68. doi:10.1097/01.crd.0000126082.86717.12

[18] Franz, R., Parks, A., Shah, K.J., Hankins, T., Hartman, J.F. and Wright, M.L. (2009) Use of autologus bone marrow mononuclear cell implantation therapy as a limb salvage procedure in patients with severe peripheral arterial disease. Journal of Vascular Surgery, 50, 1378-1390. doi:10.1016/i.jvs.2009.07.113

[19] Huang, P.P., Yang, X.F., Li, S.Z., Wen, J.C., Zhang, Y. and Han, Z.C. (2007) Randomised comparison of G-CSF mobilized peripheral blood mononuclear cells versus bone marrow-mononuclear cells for the treatment of patients with lower limb arteriosclerosis obliterans. Thrombosis and Haemostasis, 98, 1335-1342.

[20] Amann, B., Luedeman, C., Ratei, R. and Schmidt-Lucke, A.J. (2009) Autologus bone marrow transplantation increases leg perfusion and reduces amputations in patients with advanced critical limb ischemia due to peripheral artery disease. Cell Transplantation, 18, 371-380. doi: $10.3727 / 096368909788534942$

[21] Bartsch, T., Brehm, M., Zeus, T., Kogler, G., Wernet, P. and Strauer, B.E. (2007) Transplantation of autologus mononuclear bone marrow stem cells in patients with periphera arterial disease (The TAM-PAD study). Clinical Research in Cardiology, 96, 891-899. doi:10.1007/s00392-007-0569-x

[22] Powell, R.J., Comerota, A.J., Berceli, S.A., Guzman, R., Henry, D.T., Tzeng, E., Velazquez, O., Marston, W.A., Bartel, R.L., Longcore, A., Stern, T. and Watling, S. (2011) Interim results from the RESTORE-CLI, a randomized, double-blidn multicenter phase II trial comparing expanded autologus bone marrow-derived tissue repair cells and placebo in patients with critical limb ischemia. Journal of Vascular Surgery, 54, 1032-1041. doi:10.1016/j.jvs.2011.04.006

[23] Cobellis, G., Silvestroni, A., Lillo, S., Sica, G., Botti, C., Maione, C., Schiavone, V., Rocco, S., Brando, G. and Sica, V. (2008) Long-term effects of repeated autologus transplantation of bone marrow cells in patients affected by peripheral arterial disease. Bone Marrow Transplantation, 42, 667-672. doi:10.1038/bmt.2008.228

[24] Padilla, L., De la Garza, A.S., Villegas, F., Esperante, S., Rojas, E., Miranda, A., Figueroa, S., Schalch, P., Krotzsch, E. and Di Silvio, M. (2003) Administration of bone marrow cells into surgically induced fibrocollagenous tunnels induces angiogenesis in ischemic rat hindlimb model. Microsurgery, 23, 568-574. doi:10.1002/micr.10208

[25] Padilla, L., Villegas, F., Glennie, G., Escotto, I., Schalch, P., Avila, G., Rodriguez-Trejo, J., Figueroa, S., De la Garza, A.S., Krotzsch, E. and Di Silvio, M. (2007) Bone marrow mononuclear cells stimulate angiogenesis when transplanted into surgically induced fibrocollagenous tunnels: Results from a canine ischemic hinlimb model. $\mathrm{Mi}$ crosurgery, 27, 91-97. doi:10.1002/micr.20289

[26] Yeh, Y. and Cummins, H. (1964) Localized fluid flows measurements with $\mathrm{He}-\mathrm{Ne}$ laser spectrometer. Applied Physics Letters, 4, 176-178. doi:10.1063/1.1753925

[27] Kvernobo, K. and Slagsvold, C.E. (1998) Laser Doppler flowmetry in evaluation of lower limb resting skin circulation: A study in healthy controls and atherosclerotic patients. Scandinavian Journal of Clinical \& Laboratory Investigation, 48, 621-626. doi:10.3109/00365518809085781

[28] Padilla, S.L., Rodriguez, T.J., Escotto, S.L., De Diego, F.J., Rodriguez, R.N., Krötzsch, E., Villegas, A., Landero, T., Carranza, H., Goldberg, J. and Di Silvio, M. (2009) Progenitor mononuclear cell transplantation derived from the bone marrow through distal retrogressive endovenous route in order to induce angiogenesis. Cirujano General, 31, 213-218.

[29] Tepper, O.M., Capla, J.M., Galiano, R.D. and Callaghan, M.J. (2009) Adult vasculogenesis occurs through in situ recruitment, proliferation and tubulization of circulating bone marrow derived cells. Blood, 105, 1068-1077. doi:10.1182/blood-2004-03-1051

[30] Lawall, H., Bramage, P. and Amann, B. (2010) Stem cell and progenitor cell therapy in peripheral arterial disease. Journal of Thrombosis and Haemostasis, 103, 696-709.

[31] Van Tongeren, R. and Hamming, J. (2008) Intramuscular or combined intramuscular/intra-arterial administration of bone marrow mononuclear cells; a clinical trial in patients with advanced limb ischemia. Journal of Cardiothoracic Surgery, 49, 51-58. 